\title{
Forma, Literatura e Narrativa Ficcional na Busca por Comunicar: Possibilidades para as Pesquisas em Educação Matemática ${ }^{1}$
}

\section{Form, Literature and Fictional Narrative in the Search to Communicate: Possibilities to the Research in Mathematics Education}

\section{Marcelo Bezerra de Morais ${ }^{\mathrm{a}}$}

a Faculdade de Educação, Universidade do Estado do Rio Grande do Norte, Mossoró, Rio Grande do Norte, Brasil morais.mbm@gmail.com

Palavras-chave:

Metodologia de pesquisa.

Literatura e educação matemática. Estética científica. Teorização.
Keywords:

Methodology of research. Literature and mathematics education. Scientific aesthetics. Theorization.
Resumo: Este artigo tem como objetivo sistematizar compreensões sobre as possibilidades e potencialidades da mobilização de narrativas ficcionais nas (e para as) pesquisas em Educação Matemática, mostrando como essas narrativas atravessaram nossos movimentos de pesquisas, potencializando levantar problematizações e pensar teorizações tanto quanto possibilitaram refletir e materializar uma forma de escrita que comunicasse na mesma medida do que se tentava comunicar textualmente. Para isso, analisaremos as compreensões que um grupo de pesquisa defende e exercita sobre a estética científica, as formas de apresentação dos trabalhos, e os modos como as artes, notadamente a literatura, podem estar presentes visceralmente em pesquisas na Educação Matemática, tomando como exemplo um exercício de escrita de uma narrativa (ficcional).

\begin{abstract}
This article aims to systematize understandings about the possibilities and potentialities of mobilizing fictional narratives in (and to the) research in Mathematics Education, showing how these narratives were present in our researches, allowing problematization and theorization as much as reflect and materialize a form of writing that communicate what was said in the text. To do this, we analyze understandings that a research group defends and exercises about scientific aesthetics, the forms of presentations of the work, and the ways as the arts, particularly the literature, may be present viscerally in research in Mathematics Education, taking as an example an exercise in writing of a (fictional) narrative.
\end{abstract}

\footnotetext{
${ }^{1}$ Esse texto é uma sistematização decorrente de duas pesquisas que receberam apoio financeiro da Fundação de Amparo à Pesquisa do Estado de São Paulo (processos no 2011/04727-7 e 2014/05379-0, Fundação de Amparo à Pesquisa do Estado de São Paulo - FAPESP).
} 


\section{Prelúdio: um grupo de pesquisa, um amplo projeto e nossos estudos nesse contexto}

O Grupo de Pesquisa História Oral e Educação Matemática (Ghoem) é um grupo interinstitucional, formado por pesquisadores de vários estados brasileiros e tem, há anos, se empenhado a desenvolver, dentre outros temas e pesquisas, um amplo projeto sobre a história da formação e atuação de professores que ensinaram e ainda ensinam matemática, intentando realizar um mapeamento - simbólico - dos acontecimentos ligados a esse tema nas mais diversas realidades e regiões do Brasil.

Foram produzidos estudos no âmago desse projeto em diversos estados brasileiros, elaborando compreensões sobre os mais diferentes aspectos relacionados à formação e/ou atuação. Alguns estudaram a formação de professores de matemática em instituições de nível superior, a formação daqueles que atuavam fora dos centros regulares de ensino, ou a formação de sujeitos que atuavam em regiões específicas do país. Outros tematizaram grupos que desenvolviam trabalhos com formação continuada de professores de matemática ou usaram como parâmetro diferentes níveis educacionais de atuação.

Os pesquisadores vinculados a esse projeto, no Ghoem, têm mobilizado e estudado a História Oral, entendendo-a como metodologia de pesquisa qualitativa e, por isso, uma união indissociável de modos de proceder com teorias que os sustentam. Entendendo desse modo, teorias e procedimentos se retroalimentam: as teorias nos fazem pensar sobre protocolos de pesquisa que, por sua vez, possibilitam refletir e analisar as teorias que guiam a determinadas ações, levando-nos a pensar novamente sobre estas. Essa metodologia faculta lidar com narrativas subjetivas daqueles que viveram os eventos que pretendemos estudar, bem como lançar mão de outras fontes importantes para realizar operações historiográficas - como pictóricas, iconográficas, escritas, entre outras -, possibilitando-nos acessar múltiplas perspectivas para entender o passado, viabilizando conhecer e elaborar versões variadas sobre os temas pesquisados.

Esse projeto não tem a pretensão, de um ou outro modo, de delimitar ou definir padrões de formação, nem tampouco concluir ou abarcar as múltiplas possibilidades formativas que acontecem e/ou aconteceram no Brasil. $\mathrm{O}$ projeto que temos chamado de Mapeamento visa perceber as nuances e a pluralidade de possibilidades formativas; as fugas e subversões, intencionais ou não, de leis, normas, regras, decretos; as rupturas e criações de alternativas de formação; as adaptações e manutenções; as histórias que vibram nos sujeitos e a pluralidade das existências desses sujeitos e histórias; vidas, forças e fluxos que circulam no macro-acontecimento que temos chamado de formação de professores de matemática. (GARNICA et al., 2011).

Vinculadas a essa proposta maior, estão nossos estudos que visam trazer à cena as histórias sobre a formação de professores de matemática no estado do Rio Grande do Norte. 
Nosso primeiro estudo, desenvolvido a partir do mestrado, visava compreender e criar uma versão histórica de como se deu a formação de professores de matemática, dos níveis correspondentes aos atuais ensinos fundamental e médio, em uma região específica do estado, a região de Mossoró, antes da criação do curso superior que passou a formar professores para ensinar matemática nessa região. (MORAIS, 2012). No doutorado, essa proposta foi ampliada e passamos a olhar para os movimentos de formação e atuação que aconteceram em todo o estado, tomando como ponto de partida para o nosso estudo as cercanias de criação dos quatro mais antigos cursos superiores de formação específica para atuar no ensino de matemática, que foram criados nas seguintes cidades: Natal (1968), Mossoró (1974), Caicó (1979) e Patu (1980). (MORAIS, 2017a). Mais recentemente, institucionalizamos um projeto que busca perceber as nuances sobre as concepções de "formação de professores" fundamentadoras dos cursos que buscavam possibilitar qualificação aos professores para atuarem no ensino de matemática nesse estado, nos níveis que correspondem ao atual ensino básico, e como esses diferentes cursos e concepções vão interferindo nas práticas de ensino de matemática vivenciadas nas instituições escolares nesse estado (MORAIS, 2017b).

Pelo caráter das pesquisas do Mapeamento - de buscar os fluxos históricos que escapam aos discursos totalizantes e hegemônicos sobre os acontecimentos, compreendendo que narrar Histórias é um processo de criação sempre subjetivo e entendendo ainda que a atribuição de significados no processo de comunicação é sempre pessoal e, portanto, comunicar de modos diferentes nos levam a compreensões diferentes -, esse grupo vem discutindo e exercitando sistematicamente, em seus estudos, formas de escritas, estéticas variadas de trabalhos acadêmicos em Educação Matemática, problematizando suas potencialidades e limitações. Além disso, o Ghoem tem estudado os atravessamentos e movimentos que podem ser provocados pelas artes - e aqui pomos em relevo a Literatura para pensar e praticar pesquisa acadêmica.

São as repercussões das preocupações com a forma e a literatura em nossos movimentos de pesquisas - notadamente no desenvolvimento do doutorado -, as compreensões elaboradas a partir delas e ainda um exercício de escrita narrativa (ficcional) empreendido que perseguiremos nesse texto, quando pretendemos contribuir para uma sistematização de ideias em torno das possibilidades e potencialidades da mobilização de narrativas ficcionais nas (e para as) pesquisas em Educação Matemática, mostrando como essas narrativas atravessaram nossos movimentos de pesquisa, potencializando levantar problematizações e pensar teorizações tanto quanto possibilitaram pensar e materializar uma forma de escrita que comunicasse na mesma medida do que era tratado nos textos. 


\section{A forma como modo de algo comunicar}

Ao ingressar nesse Grupo de Pesquisa, um dos maravilhamentos ${ }^{2}$ que vivenciamos, foi em relação à forma de elaboração textual de alguns trabalhos do grupo; ao modo como pesquisas foram materializadas em relatórios, dissertações e teses. Nesse grupo de pesquisa já foram produzidos inúmeros trabalhos que usam recursos linguísticos e literários ou subvertem conceitos e noções - muitas vezes cristalizados - transformando-os num modo diferente de construir seus trabalhos ${ }^{3}$.

No projeto Mapeamento, por exemplo, uma pesquisadora construiu a tese em três tomos distintos, não havendo uma ordem lógica e pré-definida para iniciar a leitura; outra pesquisa foi escrita emulando uma colcha de retalhos; em outra a pesquisadora elaborou uma nova memória a partir das narrativas que tinha constituído na pesquisa. Houve dissertação em que a pesquisadora criou uma orientação fictícia para explicar e discutir como se deu a construção de seu trabalho. O recurso ficcional foi também mobilizado por mais duas pesquisadoras: uma delas, ao usar a ideia de fragmentos, criou quatro personagens para ajudála a discutir sobre a identidade do grupo que estava pesquisando, a outra utilizou o recurso da escrita epistolar e trocou cartas com um historiador fictício. Outro recurso de estilo mobilizado no grupo foi o multipaper, com cada um de seus artigos composto por autores, sendo vários os outros, para reforçar a noção de que um trabalho é sempre desenvolvido de forma coletiva. Foram ainda construídos um jogo caleidoscópico para discutir o projeto Minerva, segundo uma concepção wittgensteiniana; e mobilizados histórias de filmes e contos literários como metáforas para a escrita de textos e/ou como inspiradores para a forma ${ }^{4}$.

Todos esses trabalhos, fragmentos do projeto Mapeamento, buscam outro modo de dizer, uma forma distinta de narrar pesquisas, de contar histórias. A busca por outros modos de narrar não se dá simplesmente para apresentar os trabalhos de forma diferente, puramente por questões estéticas ou, tampouco, para o trabalho parecer mais interessante, bonito, ou ainda para a leitura ser mais agradável - isso, se acontece, é uma consequência desses exercícios de escrita. A intenção em buscar outras formas para os trabalhos, outros modos de dizer, é a de que essas elaborações textuais distintas ajudem a teorizar e defender ideias e noções específicas. (GARNICA et al., 2011; GARNICA, 2015).

\footnotetext{
${ }^{2}$ Mobilizamos a noção de maravilhoso de Greenblett (1996). Esse é um dos principais conceitos trabalhados por esse autor, que, segundo ele, seria o impacto causado pelo primeiro encontro com algo desconhecido, sendo, também, o primeiro passo para a apropriação do novo.

${ }^{3}$ Conhecemos muitos outros trabalhos e grupos de pesquisa em Educação Matemática que problematizam e exercitam outras estéticas científicas - como podemos citar, a título de exemplo, os grupos de pesquisa História, Filosofia e Educação Matemática (da Universidade Estadual de Campinas), Travessia (da Universidade Federal de Juiz de Fora) e Linguagem, Experiência e Formação (da Universidade Estadual Paulista). Aqui, contudo, temos a pretensão de problematizar as compreensões, sistematizações e modos de proceder do Ghoem.

${ }^{4}$ Os trabalhos que realizaram esses diferentes exercícios de estilo são, respectivamente: Baraldi (2003), Gaertner (2004), Seara (2005), Galetti (2004), Silva (2007), Fernandes (2011), Souza (2011), Pinto (2014), Toiller (2013) e Fernandes (2014).
} 
A busca por formas distintas de comunicar não acontece por obrigação ou de modo leviano; ao contrário, quando há, se dá de maneira fundamentada e refletida, a partir da necessidade de comunicar ideias diferentes, que podem ser potencializadas por exercícios distintos de construção textual. Isso porque as formas, para o Ghoem, não são simplesmente formas "em si", mas, sim, modos de expor, de fazer, de ser, de problematizar e teorizar, pois, para esse grupo, teorizações, tanto quanto problematizações, são ações feitas de modo intencional e a partir de invenções.

Entendemos que falar sobre algo "de modo diferente" não é, simplesmente, dizer a mesma coisa de forma diferente, mas, sim, dizer coisas diferentes, possibilitando atribuir significados distintos e construir outros conhecimentos (BRUNER, 1997; 2014; GARNICA, 2015). Apresentar um trabalho escrevendo-o de um modo diferente é, portanto, uma maneira de tentar comunicar outras coisas e, concomitantemente, estudar quais potencialidades têm essas formas para comunicar aquilo que o pesquisador deseja, problematizando como essas formas podem apoiar os fazeres acadêmicos.

Estando imbuídos dessas noções, realizamos, no mestrado, uma nova tentativa de escrita: propusemos a subversão da noção de quebra-cabeça para pensar o modo de produção historiográfica que havíamos efetivado e como a entendíamos. A sugestão era usar o jogo de quebra-cabeças como metáfora para pensar esse projeto de amplo espectro do grupo, pensando, a partir daí, os projetos como peças de um grande jogo, no qual cada peça era, em si, um novo jogo, formado por outras peças. Para propor essa metáfora era necessário desconstruir a noção usual de quebra-cabeças, propondo pensar um novo jogo no qual as peças não precisam necessariamente se encaixar de forma perfeita; um jogo em que as peças têm tamanhos e formatos distintos; em que há peças existentes e inexistentes; peças que montam (ou não) outras peças; e que não formam, obrigatoriamente, imagens perfeitas, mas, sempre, imagens plausíveis, possíveis de atribuir algum significado, sendo, elas próprias, resultados de atribuições de significados; um quebra-cabeças que nunca se fecha, nunca se completa, se regulariza, ou se cristaliza, que não tem, portanto, a intenção de ser totalizante e único. Assim, para montar um quebra-cabeças possível sobre nosso tema de estudo, criamos quatorze textos, quatorze "peças", em que cada uma delas, assim como a de um quebracabeças usual, era única, e, portanto, tinha um estilo de escrita único, com suas próprias metáforas, técnicas textuais e estilos. Como propusemos, entendíamos que as peças desse novo quebra-cabeças, assim como ele próprio - e a própria história que pretendíamos narrar -, eram peças sempre passíveis de formar novas formas, formas outras, mas, sempre em movimento, sempre em devir (MORAIS, 2012).

A intenção de subverter a ideia e a forma do quebra-cabeças, escrevendo, inclusive, de modos distintos cada texto, era a de materializar, tanto quanto possível, o modo como 
entendíamos as histórias que pretendíamos narrar: embora parecessem fixas, estáveis e imutáveis, eram invenções que podiam ser repensadas e recriadas, tomando novas formas, mostrando mais e mais o fluxo em que se vive (WHITE, 1994; ALBUQUERQUE JR., 2009; 2011). Ambicionávamos mostrar que aquelas peças eram peças possíveis, mas que, certamente, existiriam muitas outras possibilidades, outras peças passíveis de serem inventadas; pretendíamos reafirmar, a cada texto, que é possível se reinventar de forma diferente e que, no limite, é isso que sempre se faz, que toda história é criação, mesmo que não se diga; e, ainda, reafirmar essa necessidade que sentimos de utilizar modos diferentes de escrever para comunicar coisas diferentes.

Nesse primeiro exercício, o que não conseguimos foi mostrar a não linearidade da história que criamos, pois, em nossa narrativa, criamos um texto-peça-história sobre a formação de professores de matemática na região de Mossoró/RN um tanto quanto estática, estanque, o que só viemos perceber mais tarde.

Com isso, iniciamos o doutorado com a concepção de que tentaria materializar, na escrita da tese, o que pretendíamos defender - fosse utilizando o modelo padrão, nos ditames sugeridos pela academia, fosse num dos modelos já exercitados pelo Ghoem, ou, ainda, em um novo. Para nós, o texto tinha que ser parte daquilo que desejávamos compor, parte do que desejávamos comunicar e defender.

Independente da forma como fôssemos escrever a tese, um dos recursos que já pretendíamos utilizar novamente, pois já o tinha feito no mestrado, era o das metáforas, fosse com filmes ou literatura, fosse como forma de construção de texto ou para desestabilizar ideias. Assim, visando melhorar o estilo de escrita e pensando na possibilidade de buscar, na Literatura, apoio para a construção dos textos que viriam a compor nosso trabalho final, começamos, de uma forma mais periódica e regular, a fazer leituras de obras literárias ou outras formas de narrativas - como, por exemplo, biográficas, epistolares, entre outras. O que não esperávamos é que aquele movimento, até certo ponto tão despretensioso, pudesse se tornar parte importante do desenvolvimento de nossa pesquisa, impulsionando-nos a pensar alguns rumos para a tese.

\section{A literatura no processo de criação de mundos, de teorização}

Entendendo que a literatura poderia "ser porta de entrada para uma sensibilidade que tem estado ausente em nosso meio de pesquisa", podendo ter, nos trabalhos, uma "participação mais visceral", nos quais "elas, efetivamente, façam parte de um movimento intencional de teorização. [E que] As narrativas criam realidades ao mesmo tempo em que os narradores são criados" (GARNICA, 2015, p. 8), foi que a literatura tornou-se um dos meios que nos moveu a pensar de dado modo e a comunicar essas compreensões, que nos ofereceu 
subsídios para um processo de sensibilização e percepção da constituição dos sujeitos, a indivisibilidade deles, a forma como pequenos momentos nos atravessam, tornando-se experiência, constituindo-nos e, assim, nos formando como e quem somos.

A literatura nos serviu para um processo de sensibilização, de percepção dos indivíduos, dos sujeitos, e de nós mesmos como sujeitos, bem como para percebermos e falarmos das histórias dos sujeitos que conosco colaboraram. Como não ser movidos a pensar na formação das subjetividades, na existência de múltiplas temporalidades e espacialidades, na experienciação, ao ler os contos de Felicidade Clandestina? Como não pensarmos na desconstrução de conceitos aparentemente fixos, na não normalidade das coisas, na inquietação frente ao que é tido como natural ao ler Elogio da Loucura? Ou ainda, como não percebermos o quanto não valorizamos os saberes individuais, o quanto tornamos menos importante experiências que não são as da academia, ou o quanto desprezamos tantas vidas e circunstâncias ao lermos qualquer uma obra que põe em foco as subjetividades? (CALVINO, 1994; 1996; 1999; LISPECTOR, 1998; 1998a; 1999a; KAFKA, 2011; MAIOR, 2012; ASLAN, 2013; QUEIROZ, 2004).

Essas "outras" narrativas nos faziam refletir tanto quanto as narrativas geradas a partir das entrevistas com os colaboradores de nossas pesquisas, nos levando a pensar nas "vidas reais", pois "mesmo as ficções mais fantasiosas, mesmo as mais impossíveis invenções da palavra-texto são potentes descortinadoras da realidade" (GARNICA, 2015, p. 9). Enquanto os textos teóricos nos mobilizavam a pensar sobre o mundo de forma abstrata, cada narrativa, incluindo as ficcionais, davam forma para as coisas do mundo real e, muitas vezes, nos ofereciam "credenciais de acesso à realidade" (BRUNER, 2014, p. 18), pois o científico, no geral, tende a ocultar ou dissolver os "caracteres existenciais, subjetivos, afetivos do ser humano, que vive suas paixões, seus amores, seus ódios, seus envolvimentos, seus delírios, suas felicidades, suas infelicidades, com boa e má sorte, enganos, traições, imprevistos, destinos, fatalidades..." (MORIN, 2014, p. 43-44). Assim, essas obras nos movimentaram a pensar, tanto quanto os textos acadêmicos, fazendo-nos perceber e propor novas concepções; impulsionaram-nos a tentar elaborar uma teorização.

O movimento de teorização, para nós, "se caracteriza como uma intenção de produzir conhecimento por meio de um relato sistematizado de experiências. Ao teorizar, contamos uma história, produzimos significados e constituímos objetos em uma direção" (SILVA; VIOLA DOS SANTOS, 2012, p. 126), ou seja, teorização é a tessitura sistematizada de alguma compreensão, conhecimento, ideia, significados atribuídos; é uma forma de criar mundos. Esse processo permite envolver a literatura por entendermos a teorização não como um movimento em que citamos autores, "sábia e cuidadosamente pré-selecionados, que dêem credibilidade à produção ou sirvam, de algum modo, como autoridade que apenas citamos de 
modo declaratório para depois abandonar" (GARNICA, 2015, p. 12). Teorização, para nós, é um processo humano, em que nos nutrimos de ideias, procedimentos e abordagens que nos sirvam para criar sentido. Entendendo desse modo, a teorização é um processo resultante de leituras, experiências, visualizações, pontos de vista, citações, impressões, discussões, conversas, ou seja, é um processo em que apresentamos os significados e os objetos que constituímos e o que serviu como base para sua construção. Certamente, é tanto resultado de "uma composição argumentativa lógico formal (se...então, se... então) quanto de um conjunto atordoante de pontos de vista caóticos" (GARNICA, 2015, p. 12). É resultado de uma racionalização individual, como também da nossa formação coletiva; é fruto tanto de nossas leituras e reflexões quanto das nossas discussões com grupos de pesquisa, colegas de disciplinas e outros sujeitos com quem nos formamos diariamente; é, portanto, resultante de uma verdadeira antropofagia: "expropriar, se apropriar, devorar e desovar, transvalorando" (ROLNIK, 1989 apud GARNICA, 2015, p. 13).

Assim tentamos agir para a teorização, sempre abertos para quaisquer elementos que pudessem nos auxiliar a elaborar e falar sobre o que pretendíamos e do modo como gostaríamos, pois "tudo o que der língua para os movimentos do desejo, tudo o que servir para cunhar matéria de expressão e criar sentido [...]", tudo o que nutrir o sujeito de modo a mobilizá-lo, levando-o para criação do novo, para nós é bem-vindo. Corroboramos, portanto, a idéia de que "Todas as entradas são boas, desde que as saídas sejam múltiplas" (ROLNIK, 1989 apud GARNICA, 2015, p. 12), entendendo que tudo o que potencializa variadas interpretações e pensamentos deve ser mobilizando em nossas pesquisas.

E nesse movimento, nesse processo de teorização, o contato com tantos autores, tantas narrativas, literárias, ficcionais, memorialísticas, históricas, começavam a apontar, para nós, outras possibilidades de histórias sobre nosso tema de estudo, a formação dos professores de matemática no Rio Grande do Norte; nos mobilizavam a perceber outros movimentos como parte dos processos desse acontecimento, que iam além dos cursos regulares, institucionais, intencionais. Essas percepções e teorizações começaram a nos mover no sentido de utilizar também elementos ficcionais para comunicar o que desejávamos.

\section{A narrativa ficcional como invenção, criação, modo de dizer}

Pelas intenções que nos cercam sobre formas de escrita, passamos a intentar usar uma escrita em estilo mais literário e uma forma de observação na qual permitíssemos nos inserir, também como forma de questionar algumas cristalizações da academia. Cabe ressaltar que reconhecemos a importância de existirem padrões, parâmetros que balizem os fazeres acadêmicos, e não é a isso que desejamos nos opor: nossas inquietações estão relacionadas às imposições, às normatizações, às regulamentações que não permitem a ação das 
subjetividades, das particularidades, das movimentações, questionamentos e criações sempre necessárias à produção dos saberes acadêmicos - corriqueiramente ausentes (MORIN, 2014; NÓVOA, 2015; GARNICA, 2015).

Entendendo que "uma forma nova permite dizer coisas novas e, nesse sentido, a subversão aos modelos canônicos das composições acadêmicas deve, cada vez mais, ser exercitada" (GARNICA, 2015, p. 11), optamos por uma escrita mais simples para nós; mais fluida, mais natural. Assim, elaboramos uma narrativa com elementos ficcionais, intentando defender o direito de buscar outras possibilidades, outras potencialidades criadoras, analisando os ganhos que poderíamos ter com outras formas de escrita, o que poderíamos criar a partir delas, o que elas nos permitiriam dizer que outra forma não permitiria e o como poderíamos criar outros mundos, permitir outros significados (GARNICA, 2015).

Esse exercício, essa narrativa ficcional permitiria experimentar as potencialidades de uma forma de narrativa, pois acreditamos que, de algum modo, "nós organizamos nossas experiências e nossa memória de acontecimentos humanos principalmente [e não exclusivamente] na forma narrativa: história, desculpas, mitos, razões para fazer e para não fazer, e assim em diante" (BRUNER, 1991, p. 4).

Víamos nas narrativas - como ainda vemos - uma forte potencialidade para a produção de conhecimento sobre nossas subjetividades, principalmente quando afirmamos nos enquadrar num paradigma de pesquisa qualitativa, pois, "narrativas são uma versão de realidade cuja aceitabilidade é governada apenas por convenção e por 'necessidade narrativa', e não por verificação empírica e precisão lógica, e, ironicamente, nós não temos nenhuma obrigação de chamar as histórias de verdadeiras ou falsas" (BRUNER, 1991, p. 4), pois "a 'verdade' narrativa é julgada por sua verossimilhança e não por sua verificabilidade" (BRUNER, 1991, p. 12), ou seja, as narrativas nos potencializam a invenção de mundos, a criação de realidades (ALBUQUERQUE JR., 2009, 2011) ou, como dizem outros, são criadoras de ficções (WHITE, 1994).

Trabalhamos com narrativas, bem como com a História, numa perspectiva que assume a natureza subjetiva e inventiva dos sujeitos que as elaboram, sejam eles pesquisadores - que narram histórias a partir de operações historiográficas -, ou colaboradores que narram suas histórias de vida a um pesquisador. Assim, assumimos e defendemos: (a) a natureza inventiva das memórias dos colaboradores, que reinventam suas histórias, seus passados, suas memórias, a partir de um presente - que é um contexto outro, novo e plural -, com novas intenções e para determinados sujeitos, neste caso, em específico, um sujeito pesquisador, e (b) a natureza inventiva e subjetiva do pesquisador, necessária à elaboração narrativa, à ligação dos acontecimentos, à interpretação de documentos, ao entendimento e compartilhamento das informações; que estão e estarão sempre presentes, mesmo que 
balizadas por determinadas técnicas, teorias e metodologias refinadas e adequadas à produção deste tipo de narrativas - sendo, inclusive, a escolha dessas, o que o levava a diferentes modos de criar -; que, portanto, permitem aos pesquisadores narrarem diferentes histórias, mesmo que tratem dos mesmos acontecimentos, pois cada um é atravessado, mobilizado e constituído por intenções e saberes de naturezas particulares. Portanto, são essas naturezas inventivas que sempre permitem aos pesquisadores narrarem histórias únicas, embora múltiplas (BRUNER, 1991; WHITE, 1994; HALBWACHS, 2006; ALBUQUERQUE JR, 2009; 2011).

Com isso, desejávamos, de um modo ou outro, elaborar um texto que possibilitasse interpretações, já que defendemos a noção de que um dos modos de organização e/ou interpretação do mundo se dá de forma narrativa (BRUNER, 1991; 1997; 2014; GARNICA, 2015). O modo de elaboração narrativa, para nós, era principalmente um modo de criarmos um mundo, possibilitarmos que nossos leitores criassem outros mundos, atribuíssem outros significados, que fossem em direção aos nossos.

\section{Uma pesquisa e seus atravessamentos: experienciando a forma, a literatura e a narrativa ficcional em Educação Matemática}

No início de nossa pesquisa de doutorado, devido às preocupações em torno da forma e o objetivo de mobilizar literatura metaforicamente, realizamos a leitura de inúmeras obras. Algumas delas nos moveram a pensar temas de nossa tese e nos fizeram produzir significados outros sobre o que estudávamos. Nesse ponto, sistematizamos um pouco desses movimentos e das teorizações provocadas a partir dessas vivências, bem como buscamos apresentar o modo como estruturamos nosso trabalho de forma que ele fosse, em forma, o que defendemos teoricamente.

Os primeiros elementos literários que nos fizeram pensar sobre nossa pesquisa partiram d'A quinta história, de Clarice Lispector, que poderia ser mobilizada para discutir a produção de narrativas históricas, posto que, nesse conto, a autora cria histórias diferentes ao narrar um mesmo acontecimento de modos distintos, o que ia ao encontro das concepções que defendemos sobre História e formas de escrita (ALBUQUERQUE JR., 2009; 2011; GARNICA, 2015).

Em outro momento, uma das obras que mais nos inquietou foi $A$ metamorfose, de Franz Kafka, pelo modo como, para nós, o autor consegue construir uma narrativa que aparentemente trata da "bestialização" do humano. Segundo interpretamos, ficou muito forte a impressão de que o personagem principal da narrativa não se percebeu como sujeito naquela metamorfose, sendo esse o processo simbólico para representar o que talvez o autor desejasse tematizar: a perda da sensibilidade em relação a si mesmo, nutrida pelos estilos de vida que 
levam os sujeitos a isso ao se enquadrar em formas e fôrmas, padrões que são sempre deformantes, em processos de individuação que anulam a subjetivação. O processo de individuação, diferente - ou quase oposto - ao processo de subjetivação, é o processo resultado de produção de massa. "O indivíduo é serializado, registrado, modelado [...] A subjetividade não é passível de totalização ou de centralização no indivíduo" (GUATTARI; ROLNIK, 2005, p. 31).

Para nós, de algum modo, isso remetia a alguns dos colaboradores de nossas pesquisas que, aparentemente, nunca tinham se percebido em processo, não pareciam ter observado, antes das entrevistas, se havia acontecido com eles algum tipo de transformação, não percebiam, no limite, a si próprios... Agora, além das baratas da história de Clarice, havia no processo de nossa pesquisa, para nossa escrita, o grande inseto da história de Kafka como possibilidade de metáfora.

Essas duas histórias ecoaram muito mais forte em nós quando, durante a produção dos dados da pesquisa, encontramo-nos com baratas reais, ao nos hospedarmos na "Casa de Apoio ao Estudante" existente em uma das cidades por onde passamos. Essa casa de apoio ao estudante é um imóvel alugado pela universidade e serve para os alunos da instituição que precisam estagiar na cidade e nela não residem. Ao depararmo-nos com a presença dos insetos naquele local direcionado aos alunos em formação e, dentre eles, também futuros professores de matemática, e sendo mobilizado pelas concepções teóricas que começávamos a formular sobre formação, subjetividade, espacialidade etc., refletimos que são essas pequenas vivências e experiências, pequenos acontecimentos que parecem não importar a alguns, que também formam os sujeitos (LARROSA, 2009; 2016).

Isso nos remeteu a pensar que nossos professores colaboradores possivelmente também passaram por experiências tão "insignificantes" quanto aquelas, mas que também, ao fim e ao cabo, os formaram, assim como nós, naquele momento, também nos formávamos em processo... E foi esse o ponto mais inquietante daquelas experiências com baratas, insetos! Observamos que, até então, não nos percebíamos em formação. Sabíamo-nos em formação, mas não observávamos e não pensávamos sobre nós próprios: até então, formávamo-nos por estarmos inseridos num ambiente institucional específico, desenvolvendo atividades próprias àquele ambiente que resultaria num fechamento desse movimento de formação.

Embora muito falássemos sobre a sensibilização no e para o processo de pesquisa, embora muito discutíssemos com os demais membros do Ghoem sobre observar-se durante a pesquisa, sobre pensar e questionar o processo, notamos que sempre nos observávamos como $o$ pesquisador e não como um sujeito que é, entre outras coisas, também pesquisador. 
Esse movimento nos remeteu às discussões de uma disciplina que havíamos feito no início do doutorado ${ }^{5}$, quando, ao discutirmos sobre o estudo do outro - que é, via de regra, o que fazem os pesquisadores em Educação Matemática - surgiram alguns questionamentos sobre por que estudar o outro: os pesquisadores genuinamente se preocupam com o outro? Tenta dialogar com ele (para entendê-lo)? Para abrir possibilidades de aceitá-lo? Para quebrar hierarquias epistemológicas? Para derrotá-lo/dominá-lo/sobreviver? Por interesse próprio? Para entender a si mesmo? E esses movimentos fizeram com que, quase que instantaneamente, nos questionássemos: Estamos perdendo nossa humanidade ao falar do outro e de nós mesmos como aquele ser distante? Estamos, como o personagem de Kafka, passando por uma metamorfose sem percebê-la? Por que falar da formação de professores?

Nesse momento remetemo-nos, então, às discussões de outra disciplina ${ }^{6}$, e do próprio Ghoem, recordando que trabalhamos numa concepção de pesquisa que se opõe à perspectiva positivista na qual o pesquisador se nega, se anula, se coloca a observar e falar do seu "objeto de estudo" de um lugar que é um lugar nenhum, neutro e imparcial; em que esse mesmo pesquisador não participa dos processos que estuda, não interfere na realidade, não tem intenções particulares com a pesquisa. Percebemos que, mesmo negando essa perspectiva, de algum modo, e em grande medida, agíamos ainda dentro dela ao nos percebermos em processo de "quase-inseto".

A partir dessa experiência, e por tudo o que estudávamos e compreendíamos, decidimos nos colocar como atores dos cenários do qual falávamos, observando, daí, que, uma das coisas que nos levou a tematizar o que problematizávamos na tese foi o fato de sermos um dos sujeitos envolvidos nos temas abordados, que os vivenciávamos, o que impactou, de um ou outro modo, nosso processo de formação, notando que uma das consequências disso era o fato desses temas nos inquietarem.

Com o objetivo de continuar buscando subsídios para pensar na forma de nosso trabalho final, criamos, com outros membros do Ghoem, um subgrupo de estudos que chamamos de Literatura e Narrativas, no qual tínhamos como intenção ler obras literárias e discutir não apenas as histórias, seus enredos, mas também, e principalmente, as formas de elaboração dos textos, os estilos, os recursos mobilizados e as técnicas, tentando perceber as possíveis intenções do autor ao narrar e o contexto em que narrava, impulsionando, daí, discussões e reflexões em torno das narrativas, dos processos de escrita e das formas de análise.

\footnotetext{
${ }^{5}$ Referimo-nos à disciplina Educação Etnomatemática: história, cultura e prática pedagógica, oferecida no PPGEM/Unesp em 2013.1, e ministrada pelo professor Roger Miarka.

${ }^{6}$ Referimo-nos a uma discussão realizada na disciplina Identidade, cultura e subjetividade, do PPGCISH/UERN, a partir do texto de Keller (1996).
} 
Uma das obras lidas e discutidas neste grupo, que também se mostrou relevante para nossa pesquisa, foi $O$ visconde partido ao meio, de Ítalo Calvino. Nessa obra, o autor fabula a história de um Visconde que, ao participar de uma guerra, é dividido ao meio. Embora tendo conseguido manter vivas as duas metades, com a divisão acontece também a separação da natureza subjetiva desse personagem: uma das metades é um Visconde do bem, a outra é o seu lado mau. O que nos inquietou é como pode ser tão absurdo pensar naquela divisão do Visconde, mas não parece absurdo propor uma formação de professores deslocada da realidade dos sujeitos em seus ambientes externos às instituições escolares. Como pensar protocolos de formação pautados na neutralidade que alguns atribuem aos pesquisadores, nos processos de pesquisa, na academia? Como para alguns poderia ser absurdo propor dividir o bem e o mal naquele Visconde, mas não ser absurdo considerar o professor separado de suas outras subjetividades de pai ou mãe - ou quaisquer outras identidades que ele tenha? Essas reflexões somaram-se às inquietações provocadas pelos insetos, reforçando a perspectiva que começávamos a elaborar sobre a formação dos professores.

Foi desses movimentos, nos questionando sobre nós mesmos, para pensar no processo de teorização do tema e, a partir dessas perguntas, das leituras e das concepções teóricas que passávamos a defender, que começamos a perceber e elaborar uma nova noção sobre a formação de professores de matemática, pois as perspectivas que levam a entender que esse é um processo que acontece exclusivamente ou de forma mais ostensiva em cursos de formação, projetados e voltados para esse fim, não possibilitam tratar outros processos de formação e, possivelmente, nem têm interesse nesses processos pessoais e subjetivos que também formam professores de matemática ${ }^{7}$.

Ficava cada vez mais claro para nós que o professor, como qualquer outro sujeito, é formado de forma coletiva, atravessado pelos tempos e espaços, pela multiplicidade de histórias até então vividas, pelos múltiplos e complexos processos internos e externos pelos quais passa, pelo manancial de recursos que recebe do meio em que está inserido, e que é a partir desses que atribui significados para o mundo, que o levam a experienciar o mundo de dado modo, tornando-o professor sempre com formação singular (MORAIS, 2017).

Foi então, a partir da leitura do conto do Visconde, e tomados pela intenção de defender a noção de formação de professores numa perspectiva de subjetivação, que tomamos uma decisão metodológica, em nossa pesquisa, em torno da textualização ${ }^{8}$ das entrevistas que

\footnotetext{
${ }^{7}$ Cabe ressaltar que em Morais (2017) apresentamos um estudo aprofundado sobre esse tema, bem como os argumentos que nos levaram a defender a noção que aqui apresentamos.

${ }^{8}$ A textualização é o processo no qual recriamos, como pesquisadores, o texto resultante da transcrição (ou degravação) das entrevistas. O texto final elaborado a partir desse processo é o texto no qual o colaborador, de algum modo, se reconhece, legitimando-o e cedendo os direitos de publicação, e o qual incorporamos no trabalho final, tornando-o público, sendo essa versão a que mobilizamos para proceder nos movimentos de atribuição de significados (SILVA; VIOLA DOS SANTOS, 2012; BARALDI, 2003).
} 
realizamos: como a textualização é um movimento livre de regras e formas preestabelecidas, estando esta, via de regra, ligada aos gostos e intenções do autor, optamos por produzir um texto que mostrasse as subjetividades dos sujeitos envolvidos no processo da entrevista, mesmo que realizando procedimentos de aprimoramento do texto, suprimindo trechos, reformulando falas, removendo vícios naturais da oralidade. Optamos, assim, por manter no texto a estrutura do momento da entrevista, em que aparecem entrevistador e colaborador, com todas as interrupções, os movimentos de idas e vindas naturais da memória e do processo de comunicação. Essa escolha contrastava, por exemplo, com a que fizemos no mestrado, em que as narrativas resultantes da textualização eram textos corridos, no qual só os colaboradores apareciam falando em primeira pessoa.

Foi no desenvolvimento desse processo que começaram a surgir as primeiras possibilidades concretas da forma que daríamos ao nosso trabalho, principalmente após a leitura de Se um viajante numa noite de inverno, também de Ítalo Calvino. Ao ler esse texto, que narra a saga de um leitor em busca do livro "ideal", aventamos a possibilidade de elaborar diferentes histórias para o processo, dividindo a tese em três tomos: no primeiro, narraríamos o processo com foco no movimento de teorização, no segundo, o foco estaria nas fontes e, no terceiro, na análise, aproximando-nos de um dos exercícios já realizados no Ghoem ${ }^{9}$. Essa intenção foi, mais tarde, reforçada com a leitura de Nove Noites, de Bernardo Carvalho, que narra a história da investigação que o autor desenvolveu em busca de desvendar os motivos da misteriosa morte de um pesquisador.

Do modo como imaginávamos, essa forma potencializaria discutir distintos modos de narrar uma história, problematizar as potencialidades das fontes, os diferentes métodos de análise e, ainda, problematizar a constituição do sujeito como sendo algo móvel, singular e concomitante. A forma potencializaria abrir diferentes discussões e trazer as múltiplas perspectivas teóricas que nos ajudavam a desenvolver a tese, o que percebíamos ser quase impossível fazer no modelo canônico, no qual temos que resumir em um capítulo, de forma linear e "natural", como uma teoria "simplesmente" é construída a partir de "algumas leituras" que constituem o nosso "referencial teórico", num movimento que, acreditam alguns, seria também "natural" para outros leitores interessados nos trabalhos que mobilizamos.

Essa forma potencializaria mostrar uma teoria sendo construída em movimento, apresentando diferentes elementos que influenciaram o processo, possibilitando falar inclusive de literatura, pois, como pomos em relevo, esta não ocupava um espaço

\footnotetext{
${ }^{9}$ Baraldi (2003) realiza um movimento dividindo a tese em três tomos. Em um deles ela traz textos teóricos e metodológicos, em outro apresenta as narrativas de seus colaboradores e, no terceiro, apresenta suas análises. Os tomos são independentes, sendo possível ler separada e isoladamente cada volume, mas eles são também interconectados por hiperlinks (na versão digital) ou referências (na versão impressa), estratégia que permitiu que os tomos se conectem a todo o momento.
} 
coadjuvante, mas era uma marca destacada que também nos movia, de um ou outro modo, nos processos de teorização.

Entretanto, outros fluxos nos fizeram repensar a forma ${ }^{10}$ e não foi difícil reformular essa forma inicial: pensamos em dividir o corpo da tese em apenas dois Tomos. As narrativas dos colaboradores, os documentos dos arquivos que seriam mobilizados nas análises e mapas que auxiliariam nas interpretações dos documentos e narrativas formariam um deles e, o outro, foi formulado apoiado em um dos textos ficcionais, o Se um viajante numa noite de inverno, tomando à forma do livro como inspiração. Assim, narramos o nosso processo de desenvolvimento da pesquisa, intercalando-o com versões históricas sobre a formação de professores de matemática no Rio Grande do Norte, pois, desse modo, tanto se mostraria o nosso fluxo de formação e todos os elementos que passam a fazer parte desse fluxo - que é um dos temas centrais de nosso trabalho - quanto se mostraria como vamos criando histórias à medida em que vamos desenvolvendo a pesquisa - que é o que falamos quando afirmamos efetuar análises desde o início do trabalho -, e como são, cada uma, a história sobre a formação de professores de matemática no Rio grande do Norte, assim como são, também, todas juntas, uma história dessa formação.

Nessa nova forma, mobilizamos como inspiração a Quinta história, pois as narrativas que elaboramos, em uma ou outra história - a do nosso processo de formação ou a da formação de professores de matemática no $\mathrm{RN}$-, seriam guiadas pela noção de que ao contar, focar, analisar coisas distintas, criamos outras histórias, falamos de outros processos, que coabitam uns nos outros. Além desse, ainda nos nutrimos em Nove Noites para o modo de narrar, posto que o autor cria uma história, mostrando sua descontinuidade ao brincar com o tempo, em idas e vindas, ora retomando alguns eventos, ora avançando em outras direções.

Assim, optamos por escrever a história sobre o nosso processo e as narrativas históricas sobre a formação no Rio Grande do Norte, elaborando textos que criam e recriam esses processos, que se movem nos fluxos dos tempos de que falam. Junto a isso, outra ideia que mobilizamos para a forma é que ela deveria nos auxiliar a reafirmar que metodologia é processo e, assim, narramos a história tentando mostrar como a metodologia foi elaborada e reelaborada em movimento.

\footnotetext{
${ }^{10}$ Após essa primeira proposta, a forma foi alterada por duas vezes: a primeira mudança ocorreu principalmente por corroborarmos uma sugestão dada pelo orientador de colocar as narrativas de nossos colaboradores como apêndices, pois, ao propormos e enviarmos exemplos de um movimento de análise, que intencionadamente englobaria diferentes exercícios analíticos, essas fontes seriam cotejadas quase que por completo; a segunda mudança ocorreu após o Exame de Qualificação desse trabalho, quando membros da banca examinadora nos fizeram perceber que pôr as narrativas em apêndice - em um trabalho que defende que a forma comunica algo era, de um ou outro modo, dar uma relevância menor àquelas narrativas. Assim, optamos por incorporar novamente as narrativas ao trabalho, entendendo que são, também, partes fundamentais do corpo dessa tese.
} 
Para exemplificar essas opções, damos o seguinte exemplo da estética final: há na tese um primeiro texto no qual começamos a narrar nossa história de um ponto temporal antes ainda do doutorado, quando ingressamos no mestrado, no qual discutimos sobre História Oral, Educação Matemática e Metodologia de Pesquisa - por terem sido os primeiros segundo uma perspectiva teórica com o qual tivemos que entrar em contato ao ingressar no Ghoem - e, além disso, abordamos também as primeiras compreensões que elaboramos sobre ação de pesquisar e nossa opção e compreensões sobre exercitar no mestrado a análise narrativa de narrativas ${ }^{11}$ - posto que durante todo o texto fizemos uso desse método de análise em nossas narrativas históricas. O capítulo da sequência que continua tratando da história da constituição do trabalho, aborda as discussões teóricas que fomos construindo ao longo do percurso do mestrado e doutorado em torno das noções de História e Memória, trazendo ainda o que entendemos por Narrativas e Experiência, ou seja, volta a algum outro ponto temporal do mestrado para abordar os temas que desejávamos para aquele texto. Além disso, é nesse texto que apresentamos como começamos a fazer as primeiras opções relacionadas às técnicas de pesquisa, também entrelaçadas com as vivências do mestrado, e como começamos a produzir os primeiros dados do estudo da tese. Embora alguns desses estudos teóricos tenham sido vividos concomitante à realização das entrevistas do doutorado, deixamos esse processo para abordar em outro texto, mostrando, daí, outro movimento de um mesmo fluxo.

A aposta nessa forma se justifica por abraçarmos a noção de que "a melhor esperança de análise hermenêutica é apresentar uma explicação intuitivamente convincente do significado do texto como um todo, à luz de suas partes" (BRUNER, 1991, p. 7), portanto, fizemos durante todo o trabalho, a partir de cada uma de suas partes, a análise do texto e daquilo que vivenciamos - que, nesse caso, diz do nosso processo de desenvolvimento da tese e das próprias histórias sobre a formação de professores de matemática no RN.

Para não dar sequencialidade a esses textos - posto que não faria sentido uma linearidade -, denominamos os "Capítulos" com palavras que tinham relação com as viagens empreendidas e com os conteúdos presentes nos textos - por exemplo, Capítulo Espaços e Capítulo Horizontes, nos quais tematizamos, respectivamente, os estudos teóricos que nos levaram a falar sobre migração e espacialidade, e os processos e perspectivas vislumbradas para constituição da tese -, que foram escritos de modo que o leitor percebesse que não está em uma sequência linear, como exemplificamos anteriormente.

\footnotetext{
${ }^{11}$ Esse movimento de análise possibilita a constituição de um texto narrativo elaborado a partir de todas as narrativas às quais teve acesso o pesquisador, sendo diferente dessas no que tange à forma. Essa nova narrativa que é do pesquisador - permite que outras compreensões sejam (re)elaboradas e apresentadas como resultados de um processo de investigação. Nessa nova narrativa, espera-se que fiquem latentes a subjetividade daquele que narra as versões das várias fontes que alimentaram a criação dela, e o eco dos narradores, o cuidado com o modo como se narra tanto quanto com o que é narrado. (BOLÍVAR et al., 2001).
} 
Além desses recursos, como escrevemos narrativamente, optamos por não citar autores no corpo do texto ou puxar notas de rodapé para as referências - como usualmente se faz -, trouxemos essas informações em notas de fim, por entendermos que esse seria mais um modo de insistirmos na defesa de que a teorização não é apenas citar autores, mas, sim, realizar muitos movimentos, sendo um deles o de "ancorar suas teorizações nas suas próprias reflexões e práticas" (D’AMBROSIO, 1996, p. 81), assim, “convidando" nossos leitores a não buscar a referência que citamos, ficando, assim como nós, mais livres delas.

Por termos problematizado nosso processo de formação para a produção da tese, lançamos mão de um outro artifício ficcional para materializar no texto esse percurso, pois, já que nosso movimento de sensibilização foi vivido durante o desenvolvimento da pesquisa no qual passamos a nos perceber como alguém em formação, como singularidade -, começamos a narrativa da tese no impessoal e, no processo, nos inserirmos no texto, como podemos ver no trecho que marca a passagem do impessoal para o plural:

\begin{abstract}
Devido a isso, esse pesquisador decidiu que não mais poderia continuar com a postura que até então tinha. Decidiu que narraria aquela história, que era a sua, não mais como se não fosse um sujeito sem intenções, em uma terceira pessoa, usando um singular, ocupando a posição de um narrador neutro, aquele que sabe tudo o que acontece mas não atribui juízo de valor, como se não tivesse corpo, sensações e sentimentos. Decidiu que não ocuparia mais a postura desse "eu" narrador; esse eu que vinha, até agora, narrando a história de um "ele", como se esse "ele" não fosse também um "eu". Assim, decidimos - ele e eu, pesquisador e narrador; nós: o pesquisador, o esposo, o filho, o irmão, o tio e todos os outros que também são nele e em mim; o orientador, o Ghoem, professores, amigos, entre muitos outros - narrar essa história, que é "minha", em um plural. [...] Doravante, passamos a falar sempre de uma forma ativa, pois nos percebemos em constante processo de formação e sem a possibilidade de separação de um ou outro "eu" que forma esse todo, esse sujeito múltiplo que somos. (MORAIS, 2017, p. 124).
\end{abstract}

Passamos a escrever em um plural, não um plural neutro, mas um plural que reafirma uma multiplicidade que fala e age nesse eu-pesquisador, que forma e é formado por tantos outros (FOUCAULT, 1979; DELEUZE; GUATTARI, 1995).

A partir desses recursos literários, ficcionais, buscamos elaborar uma tese que fala de nós e do nosso trabalho, mostra nosso processo e o que defendemos. A tese é, em si, como defendemos, nossa metodologia: o processo; a articulação coerente entre teoria e prática, além de demonstrar, em forma, o que entendemos por teorização: o resultado de uma antropofagia de tudo a que tivemos acesso durante o processo.

\title{
À guisa de conclusão: as potencialidades de uma escrita
}

Nossas preocupações com a forma, a aproximação à literatura e os interesses nos trabalhos com narrativas, na escrita narrativa - também ficcional -, nos possibilitou vivenciar um processo de pesquisa que foi fortemente atravessado por esses elementos, seja no movimento de elaborar e reelaborar a pesquisa, no de teorização ou mesmo de sistematização 
desses percursos. O exercício final que empreendemos, de elaboração de uma narrativa ficcional, tenta imprimir na forma, tanto quanto possível, essas preocupações e atravessamentos.

As narrativas, de um modo geral, figuram no primeiro plano de todo o desenvolvimento de nossas pesquisas, potencializando produzir conhecimento sobre nossas subjetividades, formações de sujeitos e acontecimentos espaço-temporais, levando-nos à invenção de dados mundos, à criação de realidades múltiplas (WHITE, 1994; BRUNER, 1997; 2014; ALBUQUERQUE JR., 2009, 2011; GARNICA, 2015).

Trazer as narrativas ficcionais, literárias e outras, à cena, mostrando o quanto foram importantes para esse estudo, é exercitar e discutir como essas obras podem nos oferecer recursos vários para compreensão de realidades, podendo estar articuladas intencionalmente de forma mais visceral em nossas pesquisas em Educação, no geral, e em Educação Matemática, mais particularmente, fazendo parte de nossos procedimentos metodológicos, de nossos movimentos de teorização e problematização, potencializando-nos criar realidades, aventar temas e formar subjetividades - tanto outras quanto nossas próprias (SILVA; VIOLA DOS SANTOS, 2012; BRUNER, 2014; MORIN, 2014; GARNICA, 2015).

Esse exercício, para nós, possibilitou materializar na tese as compreensões que temos elaborado sobre narrativas, memória, História, historiografia, fontes e análises, bem como metodologia, problematização e teorização, não apenas afirmando o que compreendemos sobre, mas exercitando-os na forma de comunicar, na escrita, materialmente, facultando outras compreensões, outras interpretações sobre o dito, o que nos permite reafirmar que comunicar algo de diferentes formas é dizer coisas diferentes, construir conhecimentos outros, quiçá novos (BRUNER, 1997; 2014; GARNICA, 2015).

\section{Referências}

ALBUQUERQUE JR, D. M. História: a arte de inventar o passado. Bauru/SP: EDUSC, 2009.

ALBUQUERQUE JR. D. M. A Invenção do Nordeste e outras artes. 4 ed. São Paulo: Cortez; Recife: Massangana, 2011.

ASLAN, R. Zelota - A vida e a época de Jesus de Nazaré. Rio de Janeiro: Zahar, 2013.

BARALDI, I. M. Retraços da Educação Matemática na Região de Bauru (SP): uma história em construção. Tese de doutorado em Educação Matemática - Universidade Estadual Paulista, Rio Claro, 2003.

BOLÍVAR, A.; DOMINGO, J.; FERNANDEZ, M. La investigación biográfico-narrativa en Educación: enfoque y metodología. Madrid: La Muralla, 2001. 
BRUNER, J. Fabricando Histórias: Direito, Literatura, Vida. São Paulo: Letra e Voz, 2014.

BRUNER, J. The Narrative Construction of Reality. Critical Inquiry. v. 18, n. 1, p. 1-21, 1991.

BRUNER, J. Actos de Significado: para uma psicologia cultural. Lisboa: Edições 70, 1997.

CALVINO, I. Marcovaldo ou As estações na cidade. São Paulo: Companhia das letras, 1994.

CALVINO, I. O visconde partido ao meio. São Paulo: Companhia das letras, 1996.

CALVINO, I. Se um viajante numa noite de inverno. São Paulo: Companhia das letras, 1999.

CARVALHO, B. Nove noites. São Paulo: Companhia das Letras, 2006.

D’AMBROSIO, U. Educação Matemática: da Teoria à Prática. Campinas: Papirus, 1996.

DELEUZE, G.; GUATTARI, F. Introdução: Rizoma. In: Mil Platôs: capitalismo e esquizofrenia. (Volume 1) Rio de Janeiro: Editora 34, 1995. p. 10 - 39.

FERNANDES, D. N. Sobre a formação do professor de Matemática no Maranhão: cartas para uma cartografia possível. Tese de doutorado em Educação Matemática - Universidade Estadual Paulista, Rio Claro, 2011.

FERNANDES, F. S. A quinta história: composições da Educação Matemática como área de pesquisa. Tese de doutorado em Educação Matemática - Universidade Estadual Paulista, Rio Claro, 2014.

FOUCAULT, M. Microfísica do Poder. Rio de Janeiro: Edições Graal Ltda, 1979.

GAERTNER, R. A Matemática escolar em Blumenau (SC) no período de 1889 a 1968: da Neue Deutsche Schule à Fundação Universidade Regional de Blumenau. Tese de doutorado em Educação Matemática - Universidade Estadual Paulista, Rio Claro, 2004.

GALETTI, I. P. Educação Matemática e Nova Alta Paulista: orientação para tecer paisagens. Dissertação de mestrado em Educação Matemática - Universidade Estadual Paulista, Rio Claro, 2004.

GARNICA, A. V. M. Ceci n'est pas un article: impressões fragmentadas sobre Arte e Educação Matemática. Zetetiké, v. 23, p. 15-39, 2015.

GARNICA, A. V. M.; FERNANDES, D. N.; SILVA, H. Entre a amnésia e a vontade de nada esquecer: notas sobre regime de historicidade e história oral. Bolema, v. 25, n. 41, p. 213-250, 2011.

GREENBLATT, S. Possessões Maravilhosas. São Paulo: EDUSP, 1996.

GUATTARI, F., ROLNIK, S. Micropolíticas: cartografias do desejo. Petrópolis: Vozes, 2005

HALBWACHS, M. A Memória Coletiva. São Paulo: Centauro, 2006.

KAFKA, F. A metamorfose. São Paulo: Hedra, 2011. 
KELLER, E. F. O paradoxo da subjetividade científica. In: SCHNITMAN, Dora Fried (orga.). Novos paradigmas, cultura e subjetividade. Porto Alegre: Artes Médicas, 1996.

LARROSA, J. Nietzsche \& a Educação. Belo Horizonte: Autêntica, 2009.

LARROSA, J. Tremores: escritos sobre experiência. Belo Horizonte: Autêntica, 2016.

LISPECTOR, C. A bela e a fera. Rio de Janeiro: Editora Rocco, 1999a.

LISPECTOR, C. A hora da estrela. Rio de Janeiro: Editora Rocco, 1998.

LISPECTOR, C. A quinta história. In: A legião estrangeira. Rio de Janeiro: Editora Rocco, 1999. p. 74-76.

LISPECTOR, C. Felicidade Clandestina. Rio de Janeiro: Editora Rocco, 1998a.

MAIOR, M. S. Kardec - A biografia. Rio de Janeiro: Record, 2012

MORAIS, M. B. Mapeando histórias: sobre as formações e a atuação de professores e o ensino de matemática no Rio Grande do Norte. Projeto de Pesquisa (Projeto de Iniciação Científica 2017-2018, DPI/PROPEG/UERN), 2017 b.

MORAIS, M. B. Peças de uma história: formação de professores de matemática na região de Mossoró/RN. Dissertação de mestrado em Educação Matemática - Universidade Estadual Paulista, Rio Claro, 2012.

MORAIS, M. B. Se um viajante... Percursos e Histórias sobre a formação de professores de Matemática no Rio Grande do Note. Tese de doutorado em Educação Matemática Universidade Estadual Paulista, Rio Claro, 2017.

MORIN, E. A cabeça bem-feita: repensar a reforma, reformar o pensamento. 21 ed. Rio de Janeiro: Bertrand Brasil, 2014.

MORIN, E. A noção de sujeito. In: SCHNITMAN, D. F. (orga.). Novos paradigmas, cultura e subjetividade. Porto Alegre: Artes Médicas, 1996.

NÓVOA, A. Carta a um jovem investigador em Educação. Investigação em educação. 2 Série, n. 3, p. 13-22, 2015.

PINTO, T. P. Projetos Minerva: uma caixa de jogos caleidoscópica. Tese de doutorado em Educação para a Ciência - Universidade Estadual Paulista, Bauru, 2013.

QUEIROZ, E. Contos. São Paulo: Ediouro, 2004.

SEARA, H. F. Núcleo de Estudo e Difusão do Ensino da Matemática - NEDEM - "Não é Difícil Ensinar Matemática”. Dissertação de mestrado -Universidade Federal do Paraná, Curitiba, 2005.

SILVA, H. Centro de Educação Matemática (CEM): fragmentos de identidade. Tese de doutorado em Educação Matemática - Universidade Estadual Paulista, Rio Claro, 2007.

SILVA, H.; VIOLA DOS SANTOS, J. R. Sobre teorização, estética ficcional e algumas aproximações entre o Modelo dos Campos Semânticos e a História Oral. In: ANGELO, C. L. 
et al. Modelo dos Campos Semânticos e Educação Matemática: 20 anos de história. São Paulo: Midiograf, 2012. p. 110-128.

SOUZA, L. A. Trilhas na construção de versões históricas sobre um grupo escolar. Tese de doutorado em Educação Matemática - Universidade Estadual Paulista, Rio Claro, 2011.

TOILLIER, J. S. A formação do professor (de matemática) em terras paranaenses inundadas. Dissertação de mestrado em Educação Matemática - Universidade Estadual Paulista, Rio Claro, 2013.

WHITE, H. O texto histórico como artefato literário. In: Trópicos do discurso: ensaios sobre a crítica da cultura. São Paulo: EDUSP, 1994.

\section{SOBRE O AUTOR}

MARCELO BEZERRA DE MORAIS. É licenciado em Matemática pela Universidade do Estado do Rio Grande do Norte (2010), mestre (2012) e doutor (2017) em Educação Matemática pela Universidade Estadual Paulista (Unesp, câmpus de Rio Claro), com período sanduíche realizado na Universidade de Lisboa (2015). Atualmente, é professor da Faculdade de Educação (FE) da Universidade do Estado do Rio Grande do Norte (UERN), do Programa de Pós-Graduação em Ensino (PosEnsino - UERN/UFERSA/IFRN), e membro do Grupo de Pesquisa História Oral e Educação Matemática (Ghoem) e do Grupo de Estudos do Pensamento Complexo (Gecom). Atua na Educação, principalmente com o desenvolvimento de atividades que problematizam o ensino de matemática e pesquisas na interface História da Educação Matemática, Ensino de Matemática e Formação de Subjetividades. Principais interesses de pesquisa: Metodologia de Pesquisa; Formação de Professores (de Matemática); Sujeitos e Subjetividades; História, Memória e Narrativas; História Oral e Educação Matemática; Cultura escolar e ensino de Matemática. 